\title{
Sustainable urban mobility: An approach to urbanization and motorization challenges in Nigeria, a case of Lagos state
}

\author{
Sodiq 0. Buhari *(D), Moses 0. Aponjolosun **(D), \\ Babatope G. Oni * ${ }^{\mathbb{D}}$, Matthew W. Sam * (D)
}

*Maritime Transport and Business Management Department, Federal College of Fisheries and Marine Technology,
P.M.B 80063, Nigeria
buhari.sodiq@gmail.com; progressoni@gmail.com; sam.matthew@fcfmt.edu.ng
** Department of Maritime Management Technology,Federal University of Technology Owerri, P.M.B 1526, Nigeria
aponmoses@yahoo.com

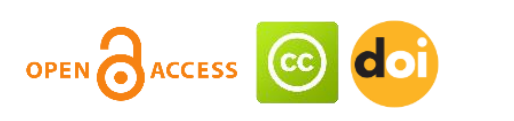

\section{Article history:}

Received: May 16, 2020

1st Revision: September 25,

2020

Accepted: November 06, 2020

\section{DOI:}

10.14254/jsdtl.2020.5-2.8

\begin{abstract}
In Lagos state, the relationship between urbanization and motorization is unbalanced because the present transportation interventions of the state do not commensurate with her growing population and migration rate. However, the state cannot be said to be totally insensitive to these challenges as witnessed in her renewed effort by providing suitable public transportation system with a dedicated lane and the expansion of other modes of transport such as rail and inland water transport. Through content analysis, this research examined the present situation of Lagos state public transport system with her prevailing population size, sustainable urban mobility approach and the future of public transport in Lagos State in line with global practices. The study reviewed the Lagos state non-motorized transport policy and the impact thus far. It was revealed that unless certain strategic decisions and policies are made, the state will continue to experience the current traffic congestion on her roads as well as increased vehicular pollution and waste of resources. Also, for Lagos state to attain her acclaimed position of a $21^{\text {st }}$ century economy, she must as a matter of policy initiate and implement interventions that align with the principle of urban mobility where cycling, walking, high capacity buses operation is effectively operational and open up of other modes of transportation in the state. It was further recommended that the Lagos state government should take a bold step as recently done in the restriction of motorcycles and tricycles operation on certain routes within the state, hence, initiating interventions that will best enhance public transportation, improve habitable environment and safety of lives and properties in the state.
\end{abstract}

Keywords: sustainable mobility, urbanization, Lagos state, transportation. 


\section{Introduction}

Urban mobility planning is a focus on people, not vehicles. Lagos State being the $5^{\text {th }}$ largest city in Africa with an estimated population of about 20 million people but unfortunately a significant number of this population are lost to road crashes and resources are wasted as a result of the present transportation system where intra-city movement are marred by consistent congestions. Ajala (2018) stated that the demand for transportation has not been met with supply, rather traffic congestion, pollution and social inequalities are the reflection of the city mobility. According to Etim (2019) the growing population due to urbanization is over the supplies and amenities Lagos state could provide. Jeekel (2017) was of the opinion that increase in the number of urban dwellers pose a great challenge in achieving sustainability. Nijkamp et al (n.d) defined sustainable transport as an acceptable level of social cost with the mobility of goods and people. Social costs can be explained in respect to damage of environmental quality such as emission of $\mathrm{CO}_{2}$ which negatively affect the quality of air or noise pollution affecting the local quality of life. Furthermore, increase in fatality rate as a result of accident or congestion which has huge effect on economic activities are categorized as the element of social cost. On the other hand, urgent steps are required to ensure more equitable allocation of road spaces by incorporating a purpose driven road design with a strong focus on walking, cycling, efficient public transport planning, design management, financing transport projects and implementation.

\section{Problem statement}

Lagos state faces varied transportation and pedestrian challenges especially as it concerns developing a public transport system that is efficient, acceptable and accessible to her growing population as well as facilitate continued economic growth. The present trend is such that the available public transportation model is insufficient for the growing motorization need. The existing and on-going dedicated lane construction could only be sufficient if government initiate interventions that encourages modal split (i.e. a situation where individual car owners drops their vehicles for public transportation). Unfortunately, government at federal and state levels are building roads for vehicles rather than for individuals which is not a catalyst for sustainable transportation system, what this means is that the current system permits individuals to have control over their journeys. The causes of the present trends are not limited to the following; increase personal vehicle ownership and ridership, lack of a pooling vehicle system, lack of a conducive environment for cycling and walking, high rate of para-transit operations, lack of 24 hours operational cities.

\section{Objectives}

By examining sustainable urban mobility in Lagos state, this study is expected to;

i. examine a sustainable environmentally friendly transport system;

ii. identify best practices in the management of traffic and reduce the rate of accidents on the road.

\section{Conceptual review}

Urbanization refers to the increasing number of people living in urban areas. It predominantly results in the physical growth of urban areas. It also symbolizes a population shift from rural to urban areas and the ways the authority adapts to this changes. More than half the world's population live in urban areas and this proportion is expected to grow (Stackey \& Hire, 2014). Urban cities cannot attain her status without providing sustainable and achievable transport management system that requires traffic management, improved public transportation, intermodal transport system and intelligent transportation system that will facilitate improved mobility and transport infrastructures.

Motorization is the act of motorizing (the movement of persons) with the use of motor vehicles/automobiles. Motorization provides individual's flexible transportation in urban areas, stifle local development, increase pollution and create unprecedented safety hazards. Without careful attention to the motorization process, disaster looms for cities of the developing world; disaster from which the industrialized countries cannot be isolated. 
Transportation means the movement of people and goods from one place to the other. It is concerned with movement and reaching destination. Transportation facilitates everything which is not limited to economic growth, wealth creation, human capital, agriculture and food security, industrialization and education. Henry Ford once cited that the United State doesn't have good roads because it's a rich country but, rich because it has built good roads. Herrero (2012) stated that transport is key to sustainable development as result of it socio-economic and environmental impact and its linkages with other sectors. Sustainable Mobility for All (2017) also alluded to the fact that the potential economic and social benefits of today's transport have been greatly eroded by social, health, environmental and economic losses associated with traffic congestion, air and noise pollution and road crashes.

Urban mobility is described as the lifeline of a modern cities, a critical economic factor, and a facilitator of smart and sustainable development. Planning a 21st century city that delivers effective and equitable urban mobility solution is one that requires innovation, collaborative eco-system approaches and strategies to meet city mobility through a safe, and secure public transport systems. Stucki (2015) posited that African cities are experiencing rapid and unplanned growth as a result of high pace of urbanization at both large and intermediate African cities. Accessibility and mobility are central to sustain urban development but most African cities display low levels of development and mobility when measured against the needs of their population (Stucki,2015). However, it must be noted that modern societies demand high degree of mobility of a variety of types essentially for adapting to social needs in order to ensure movement of people and goods in a safe environmentally friendly and economically efficient manner (Herrero, 2012). Sustainable development simply means meeting the needs of the present without compromising the ability of future generation to meet their needs (John, 2019). United Nations Secretary-General's High level Advisory Group on Sustainable Transport (2015) pointed out that sustainable transport drives sustainable development which is fundamental to meeting the needs of people in respect to their personal and economic lives while respecting the ability of the future generations to meet their needs.

\section{Urbanization and Motorization in Lagos state}

In Lagos State, there is substantial gap between the number of people using public transport in the cities and the available public infrastructure. This gap is as a result of the following:

i. Significant growth in the urban population and influx in recent decades,

ii. Excessive number of privately owned vehicles on the roads,

iii. Lack of sustainable and effective public transport network,

iv. Urban Mobility Challenges,

v. Ineffective relationship between transportation and land use planning,

vi. Lack of parking management approach,

vii. Absence of long term/sustainable plan for transport system in the State.

There is need for the Lagos state government commitment in road design, road construction and expansion, urban planning; evident in the present administration is her "Traffic Management and Transportation" agenda targeted at improving the transportation network in the state in a bid to provide sustainable urban mobility in the state. This call if well conceptualized and implemented will signal Lagos as a model for other states of the federation.

This is a wakeup call to attract strategies and innovations that are targeted at alleviating transportation challenges in Lagos state with the prime motive of consolidating on existing bus reform model, improving traffic situation and promoting sustainable environment by stimulating effective public transportation system. Uma et al (2014) stated that transport infrastructure restructuring can be said to be positively related to alleviation of poverty considering the multiplier effect of its establishment in employment creation, productivity increase and income generation

Achieving sustainable energy-efficient and environmentally friendly transport systems is one of the global key aim. Sustainable Urban Mobility Plans (SUMPs) are instruments that contribute to reaching the climate and energy targets set by EU leadership. However, cities frequently face major barriers while creating their own sustainable urban mobility plans. Hence, the way out for the attainment of sustainable urban mobility is that public transportation must be designed to include 
cycling and walking as a better approach for transportation enhancement. The call for sustainable mobility is also supported by the following:

1. UN Resolutions on Public Transportation

2. The New Urban Agenda, 2016

3. 7 Targets of the Sustainable Development Goals (SDGs), 2016

4. The Future we want; Transport as a fundamental element in human development, 2012

5. UN High Level Committee on Sustainable Transport

6. The World Bicycle Day, $12^{\text {th }}$ April, 2018

According to Pojani and Stead (2015) cities in developing countries are confronted with a rapid growth in transport-related challenges such as pollution, congestion, accidents, public transport decline, energy deletion and environmental degradation. Increase in the usage of car is aid to outpaced the development of urban road network with a growing concern of increase in pollution and urban environmental destruction due to the expansion of road infrastructure as necessitated the need for sustainable mobility which sought to ensure the mobility of population by reorienting transport demand towards safe and more environmentally friendly modes of transport (UNECE,2019). All of these point to one thing, that the car has become much of an enemy to humanity and the time is now to diversify to sustainable mode of transport.

The present operational transportation situation in Lagos state with the attendant vehicular and human population growth contributed to the incessant traffic congestion experienced on our roads on a daily basis as the operators are equally constituting public nuisance by flaunting traffic rules and regulations, environmental pollution, loss of man hours. Also, it threatens the safety of lives and properties and ultimately have negative impact on direct and indirect investment opportunities for the state thereby eroding public confidence in public transportation. Unless urgent and strategic steps are taken to address the status quo, we might be far from attaining the level of a $21^{\text {st }}$ century city has been projected by the present administration and this will further worsen the current traffic situation being witnessed in the Lagos state.

Furthermore, an evidence of one of the sustainable urban mobility is the relative peace and orderliness experienced on Ikorodu road which can be attributed to the operations of high capacity buses under the supervision of Lagos Metropolitan Transport Authority (LAMATA), Primero Transport Services and the recently introduced Lagos state Bus Service Limited (LBSL), an effort to consolidate the bus reform initiative. Hence, there is need for Government to consolidate on this approach by expanding her operational modalities to accommodate new investors or stakeholders.

The Lagos state government with her attendant challenges is expected to put structure/regulation in place as part of effort to implement the principle of sustainable urban mobility and to consolidate on her cardinal focus, hence, the Lagos state government should note that, the only way to encourage investment in the existing bus rapid transit (BRT) scheme is to enhance the operation by injecting more high capacity buses into the scheme and develop policy that are self-sustaining.

Successive government and governance in Lagos state understood the important of transportation especially public transport and has over the years developed strategies aimed at improving the public transport sector of the State. Hence, there are established effort by the state government and more importantly the present administration as witnessed in her Traffic Management and Transportation; Health and Environment; Education and Technology; Making Lagos 21 ${ }^{\text {st }}$ Century state; Security and Governance (T.H.E.M.E.S) agenda. However, the capital and labour investment placed on all modes of transport by Lagos state is an evidence that the government is actually targeting a sustainable urban mobility in line with the Global approach but more still needs to be done in areas of policy, political will and implementation of sustainable interventions.

It is important to specifically state some of the Lagos state government interventions and projects aimed at improving public transportation in the State which are not limited to the following:

a. The establishment of Lagos state Metropolitan Area Transport Authority (LAMATA) as the core regulatory body for Bus Rapid Transport (BRT) scheme in the state. Thereby ensuring that public transportation in Lagos State is redefined and operated in line with global standard.

b. The on-going construction of Lagos Rail Mass Transit (Urban Rail System) being managed by LAMATA is also an attempt by the State Government to promote sustainable urban mobility and decongest the roads. 
c. The development on non-motorized transport policy by the Lagos State Government in a bid to promote non-motorized transport and achieve zero pedestrian death in the State. This when fully implemented will see pedestrian and cyclists frequently walk and ride simultaneously on the carriage way sharing same road with motorized transport.

d. The re-engineering and re-vitalization of water transportation in the State especially the on-going interventions by Lagos State Water Authority (LASWA), Lagos State Ferry Service (LAGFERRY).

e. Continuous and consistent maintenance of roads, Construction of new ones, Expansion of road networks, re-configuration of roundabouts, Installation of road furniture, signage, signals and other infrastructures within the State.

Consequent upon the Lagos state interventions and investment in the public transportation, the situation is still not giving the expected result as individual still want to have control over their journeys (i.e. a situation where the member of the public want to drive their individual cars) thereby compounding traffic situation despite government effort of over the years. Hence, the need for a more concerted effort as it relates to policy formulation, pronouncement and political will to implement the sustainable urban mobility plans.

\section{Sustainable urban mobility and strategies}

It is pertinent to mention the 10 principles of sustainable urban mobility to capture Government strategies and initiative towards achieving them and they are as follows:
i. Developing Transit-Oriented cities
ii. $\quad$ Planning dense and human scale cities
iii. Optimizing the road network and its use
iv. $\quad$ Encouraging walking and cycling
v. Controlling vehicle-use
vi. Implementing transit improvements
vii. Managing parking
viii. Promoting clean vehicles
ix. Communicating solutions
$\mathrm{x}$ Approaching the challenges comprehensively.

In respect to the above stated principles, model for sustainable urban mobility is expected to cover bus rapid transport, light rail, tram, electrification, cycling and walking. Furthermore, some of the essential benefits of adopting sustainable urban mobility to solve the challenges of our increasing urbanization and motorization include the following:
a. Reduction in road congestion
b. Reduction in travel/journey time,
c. Promotion of safe and convenient means for movement,
d. Reduction in pollution and improved healthier environment,
e. Facilitation of intermodal transport system.

To transit from the existing transportation system to a sustainable mobility plan, the following strategies are required:

i. We need to start building cities for people who are the original owners and stop building cities for cars,

ii. Develop policies on population growth and address urbanization (that is, control of child birth),

iii. Provision of transport facilities that cater for persons living with disability, elderly and other vulnerable members of the society,

iv. Massive investment in infrastructure provision. 


\section{Global comparism of applicable sustainable urban mobility}

It is pertinent to highlights and compare some major cities/countries around the world that has adopted the sustainable urban mobility principles in a bid to provide efficient transportation system for their growing population. This comparism is clearly shown in Table 1 below.

\begin{tabular}{|c|c|c|c|c|c|}
\hline $\mathrm{S} / \mathrm{N}$ & Country & & $\begin{array}{l}\text { Cycling And Walking } \\
\text { (Non-Motorized } \\
\text { Transport) }\end{array}$ & $\begin{array}{c}\text { High Capacity } \\
\text { Vehicles Operations }\end{array}$ & $\begin{array}{c}\text { Restriction Of Small } \\
\text { Capacity Vehicles On } \\
\text { Major Roads (Limited } \\
\text { Vehicles Movement) }\end{array}$ \\
\hline 1 & Kenya (Nairobi) & & YES & YES & YES \\
\hline 2 & Uganda (Kampala) & & YES & YES & YES \\
\hline 3 & Ghana (Accra) & & YES & YES & YES \\
\hline 4 & $\begin{array}{l}\text { Brazil (Rio and } \\
\text { Horizonte) }\end{array}$ & Belo & YES & YES & YES \\
\hline 5 & England & & YES & YES & YES \\
\hline 6 & Tanzania(Dar es Salam) & & YES & YES & YES \\
\hline 7 & France & & YES & YES & YES \\
\hline 8 & $\begin{array}{l}\text { Morocco (Casablanca } \\
\text { Rabat-Sale) }\end{array}$ & and & YES & YES & YES \\
\hline 9 & USA (New York) & & YES & YES & YES \\
\hline
\end{tabular}

\section{Recommendations}

Challenges associated with urbanization could be addressed by adopting the following recommendations/approaches:

a. A shift in transport mode and policies that promote the use of public transport through the establishment of metropolitan transport system (a case of LAMATA) and Light Rail systems (Blue and Red lines),

b. Consolidate the interests of various stakeholders in the urban mobility sector, thereby minimizing complexities,

c. Adopting Intermodal transport system through the revitalization of other modes of transportation (i.e. rail and inland water transport),

d. Effective planning of transport route (i.e. urbanized areas with effective public transport, network) by restricting small capacity buses to accommodate high capacity vehicles,

e. Encourage non-motorize transport in order to improve traffic flow and promote cleaner environment (i.e. walking and cycling for last mile transport),

f. Implement the principle of urban mobility,

g. Implement transport policies, guidelines and a long term urban mobility network plan,

h. Government should employ a policy where car sharing will be adopted for routes where road constructions are on-going. This is in a bid to reduce the number of vehicles on such routes,

i. Subject to above, Government across boards should deploy more high capacity buses that are efficient and effective to areas in a bid to discourage individual vehicles on such routes and encourage public transportation,

j. Enforcement of traffic rules and regulation.

\subsection{Proposed interventions}

In addition to the above stated recommendations, this study is proposing the following specific measures for sustainable mobility in Lagos state on a short/medium and long term basis.

\section{Short/Medium Term Plan "A"}

i. The Lagos State Government is expected to open up relationship with critical high capacity public transport operators in a bid to audit their operations and capacities to meet up with the State transport demand and subsequently develop a model for expansion in order to capture the deficit. 
ii. On the implementation of " 1 " above, there will be need to immediately engage Transport Unions (National Union of Road Transport Workers(NURTW) and Road Transport Employers Association of Nigeria(RTEAN)) on the need to restrict the operations of mini-buses "Danfo" from the concerned major roads to inner roads/routes.

iii. The audit and expansion scheme shall be for three months (i.e. High capacity vehicle operations for concerned major routes and "Danfo" for inner roads/routes).

iv. Creation of public awareness/enlightenment through media.

v. Engagement and partnership with relevant stakeholders on the enforcement of the scheme.

\section{Short/Medium Term Plan "B"}

i. (If) Government and her stakeholders (road transport operators, road transport unions, etc.) cannot meet up with the carriage capacity, the operation shall be such that only high capacity vehicles will operate on the major roads/routes and restrict mini buses "Danfo" to inner roads only.

ii. (If) the above mentioned stakeholders cannot meet up with the carriage capacity, the operations shall be for peak and off- peak period (i.e. the high capacity vehicle will operate during peak period in the morning and evening " $5 \mathrm{am}-10 \mathrm{am} / 4 \mathrm{pm}-10 \mathrm{pm}$ " and mini buses "Danfo" will operate during off-peak period "10am-4pm and 10pm-4am").

\section{Long Term Plan}

i. Engage relevant Ministry, Department and Agencies (MDAs) to accommodate the various non-motorist lanes in certain road projects that requires them (i.e. cycling and pedestrians' lane) in a bid to promote sustainable urban mobility,

ii. Engage critical stakeholders on the swift implementation of the programme.

iii. Engage private sectors on the operation of public transportation in the state by coming on board with only high capacity buses in a bid to phase out "Danfo" from all major roads/routes.

iv. The programme should be implemented in phases with priority on the corridors with much traffic concerns.

v. "Danfo" and other small capacity buses operations should be permanently restricted to inner routes when all major roads in the state are fully covered by the scheme.

vi. The operators should be licenced in line with best practice and the Government existing regulations and extant Laws.

vii. Strict compliance to the proposed operations and imposed movement/congestion tax on "Danfo"/small capacity buses that wishes to ply the restricted route at any point in time (i.e. that is small capacity commuter vehicles on "chartered operation").

\section{Conclusion}

Urbanization is occurring rapidly as a result of unprecedented migration from other states to Lagos state. The rate of urbanization and motorization in Lagos state present a great deal of concern as the transport infrastructure and services are at levels that cannot support the growing population. Also, adequate provisions are yet to be made in respect to non-motorized mobility in the state and the existing bus public transport is highly fragmented with multiple private operators, operating the small buses of poor quality in an unregulated environment. It must be noted that for Lagos state to overcome the challenges posed by urbanization and achieve sustainable mobility the interventions as proposed in this study should be applied.

\section{Funding}

The authors received no direct funding for this research. 


\section{Citation information}

Buhari, S. O., Aponjolosun, M. O., Oni, B. G., \& Sam, M. W. (2020). Sustainable urban mobility: An approach to urbanization and motorization challenges in Nigeria, a case of Lagos state. Journal of Sustainable Development of Transport and Logistics, 5(2), 90-97 doi:10.14254/jsdtl.2020.5-2.8.

\section{References}

Ajala, A.T. (2018). Conceptualising Smart City for the Development of Nigeria's Urban Transportation. Advances in Multidisciplinary \& Scientific Research Journal, 4(2), 65-72.

Etim, E.J. (2019). Poor Public Transport Infrastructure in Lagos, Nigeria, how Sustainable improvement could enhance well-being of people and provide environmental benefits. Bachelor degree thesis.

Herrero, L.M. (2011). Transport and Mobility: the keys to Sustainability. Accessed 04/05/2020. Available at www.fgcsic.es/lychaos/en_EN/articles/transport_and_mobility

Jeekel, H. (2017). Social sustainability and smart mobility: Exploring the relationship. Transportation Research Procedia, 25, 4296-4310.

Nijkamp, P., Verhoef, E., Ubbels, B., \& Rodenberg, C. (n.d). Sustainable Mobility. Transportation Engineering, vol. ll.

Pojani, D., \& Stead, D. (2015). Sustainable urban transport in the developing world: beyond megacities. Sustainability, 7(6), 7784-7805.

Stucki, M. (2015). Policies for Sustainable Accessibility and Mobility in Urban Areas of Africa. Africa Transport Policy. Accessed 07/06/2020. Available at http://documents.worldbank.org/curated/en/467541468191641974/pdf/95606-REVISEDPUBLIC-SSATPWP106-Urban-Mobility-IO.pdf

Sustainable Mobility for All. (2017). Global Mobility Report: Tracking Sector Performance. Washington DC, License: Creative Commons Attribution CC BY 3.0

Starkey, P., \& Hine, J. (2014). Poverty and sustainable transport: How transport affects poor people with policy implications for poverty reduction. A literature review.

Uma, K.E, Onwusogbulu, R.D., \& Enwere, G.M. (2019). The need for Transport Infrastructural Restructuring in Nigeria: A step to Sustainable Development. Journal of Emerging Trends in Economics and Management science.

United Nations Secretary General's High Level Advisory Group on Sustainable Transport (2015). Mobilizing Sustainable Transport for development. Available at https://sustainabledevelopment.un.org/index.php?page=view\&type=400\&nr=2375\&menu=1515 UNECE. (2019). UNECE Handbook on Sustainable Transport and Urban Planning. Available at https://thepep.unece.org

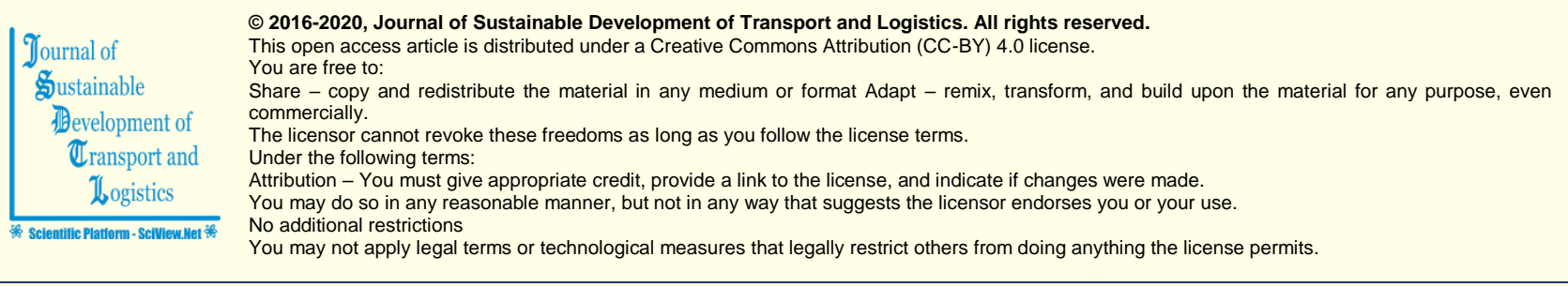

Journal of Sustainable Development of Transport and Logistics (ISSN: 2520-2979) is published by Scientific Publishing House "CSR", Poland, EU and Scientific Publishing House "SciView", Poland, EU

Publishing with JSDTL ensures:

- Immediate, universal access to your article on publication

- High visibility and discoverability via the JSDTL website

- Rapid publication

- Guaranteed legacy preservation of your article

- Discounts and waivers for authors in developing regions

Submit your manuscript to a JSDTL at https://jsdtl.sciview.net/ or submit.jsdt|@sciview.net 